\title{
KELAYAKAN POWERPOINT INTERAKTIF ORGAN TUMBUHAN KELAS XI SMA BERDASARKAN ANALISIS UKURAN DAN TIPE STOMATA
}

\author{
Dhea Vivin $K^{1}$, Entin Daningsih ${ }^{2}$, Reni Marlina ${ }^{3}$ \\ ${ }^{1,2,3}$ Program Studi Pendidikan Biologi, FKIP, Universitas Tanjungpura \\ Jalan Prof. Dr. Hadari Nawawi Pontianak 78124 \\ 'e-mail: dhevinka_dhea@yahoo.co.id
}

\begin{abstract}
Abstrak
Penelitian bertujuan untuk mengetahui kelayakan powerpoint interaktif organ tumbuhan sebagai media pembelajaran yang berisi informasi dari hasil analisis ukuran dan tipe stomata tanaman di Kota Pontianak. Penelitian menggunakan deskriptif kuantitatif. Pengumpulan data dilakukan menggunakan instrumen validasi, untuk ahli materi berisi 3 aspek dan 7 kriteria, sedangkan untuk ahli media berisi 6 aspek dan 10 kriteria. Proses validasi dilakukan oleh tiga orang ahli materi dengan hasil validasi yaitu Rata-rata total validasi $\left(\mathrm{RTV}_{\mathrm{TK}}\right)$ sebesar 3,45 dan tiga orang ahli media dengan hasil validasi yaitu $\mathrm{RTV}_{\mathrm{TK}}$ sebesar 3,70 . Baik validasi materi maupun media secara keseluruhan powerpoint interaktif dengan menggunakan informasi dari hasil analisis ukuran dan tipe stomata tanaman di Kota Pontianak layak digunakan dalam proses pembelajaran pada sub materi organ tumbuhan di kelas XI SMA.
\end{abstract}

Kata Kunci: kelayakan, powerpoint interaktif, ukuran dan tipe stomata.

\begin{abstract}
This study aimed to determine the feasibility of interactive powerpoint of plant of organs as learning media which have been contained information from the analysis of the size and type of plant stomata in Pontianak City. This research was a quantitative descriptive research. The data were collected using a validation instrument, material experts was contained 3 aspects and 7 criterias, and for media experts was contained 6 aspects and 10 criterias. The validation process was done by three persons of material experts with the validation result of Average Total Validity $\left(R T V_{T K}\right)$ was 3.45 and three person of media experts with the validation result of $R T V_{T K}$ was 3.70. Both material and media validation overall, interactive powerpoint by using information from the analysis of the size and type of plant stomata in Pontianak was feasible to be used in the learning process on plant of organs in sub material in grade XI SMA.
\end{abstract}

Keywords: feasibility, interactive powerpoint, size and type of stomata.

\section{PENDAHULUAN}

Penggunaan media pembelajaran dalam pendidikan sangat mendukung proses kegiatan belajar mengajar. Media juga dapat mengatasi keterbatasan ruang, waktu, dan indera serta membangkitkan motivasi dan minat belajar siswa (Djamarah dan Aswan, 2010; Sanjaya, 2008; Daryanto, 2010). 
Salah satu bentuk media pembelajaran yaitu powerpoint. Menurut Maryani (2014) multimedia berbasis powerpoint merupakan penggunaan komputer untuk menyajikan dan menggabungkan teks, suara, gambar, animasi dan video dengan alat bantu (tool) dan koneksi (link) sehingga pengguna dapat bernavigasi, berinteraksi, berkarya dan berkomunikasi.

Kelebihan media powerpoint adalah memiliki variasi teknik penyajian yang menarik dan tidak membosankan, materi pembelajaran disampaikan secara utuh melalui pointer-pointer materi, praktis (bisa untuk semua ukuran kelas), dapat digunakan berulang-ulang, dan dapat menggabungkan semua unsur media, seperti teks, video, animasi, gambar, grafik, dan suara menjadi satu kesatuan penyajian sehingga dapat mengakomodasi siswa yang memiliki tipe visual, auditif, maupun kinestetis (Mangkulo dalam Suyono dan Nugroho, 2011; Sanjaya, 2008; Nisa, 2012; Kenthut, 2010).

Media powerpoint dapat digunakan untuk menjelaskan materi-materi yang bersifat teoretis sehingga memudahkan pemahaman siswa serta membantu sebuah gagasan menjadi lebih menarik sehingga efektif dalam meningkatkan motivasi dan hasil belajar siswa. Hal tersebut dibuktikan dalam penelitian Raras (2012), penggunaan media powerpoint pada mata pelajaran IPA dapat meningkatkan motivasi dan hasil belajar siswa dengan rata-rata hasil belajar 86,06. Hasil penelitian Asmadji (2012), dengan menggunakan media pembelajaran powerpoint pada mata pelajaran IPA dapat meningkatkan hasil belajar siswa yaitu mencapai $90 \%$.

Media powerpoint memiliki kekurangan, yaitu (Sanaky dalam Raras, 2012; Nisa, 2012; Kenthut, 2010): (1) Tidak semua sekolah dapat memiliki komputer dan proyektor dikarenakan biaya pengadaannya mahal; (2) Guru harus terampil dalam mengoperasikan komputer dan mendesain slide powerpoint sehingga mudah dipahami oleh peserta didk; (3) Memerlukan persiapan yang matang jika menggunakan teknik-teknik penyajian (animasi) yang kompleks; dan (4) penggunaannya terkait pada ketersediaan listrik.

Penggunaan media powerpoint interaktif dapat membantu siswa memahami materi pembelajaran, salah satunya materi struktur dan fungsi jaringan jaringan 
tumbuhan pada sub materi organ daun dengan salah satu modifikasi jaringannya berupa stomata. Pada proses pembelajaran yang dilakukan, pengamatan untuk stomata jarang dilakukan. Materi pelajaran tentang stomata juga hanya sebatas mengenai struktur dan fungsi stomata. Pada penelitian yang dilakukan, powerpoint interaktif yang dibuat digunakan sebagai media untuk membantu jalannya proses pembelajaran dan memberikan informasi tambahan tentang ukuran dan tipe stomata. Pengertian interaktif terkait dengan komunikasi dua arah atau lebih dari komponen-komponen komunikasi yaitu hubungan antara manusia (sebagai user/ pengguna produk) dan komputer (software/ aplikasi /produk dalam format tertentu).

Berdasarkan permasalahan yang telah diuraikan, maka penelitian bertujuan untuk menguji kelayakan media powerpoint interaktif pada sub materi organ tumbuhan di kelas XI SMA.

\section{METODE}

Metode penelitian yang digunakan adalah deskriptif kuantitatif. Penelitian dilakukan dalam 2 tahap, yaitu pembuatan media powerpoint interaktif dan validasi media powerpoint interaktif sebagai media pembelajaran. Alat yang digunakan dalam penelitian adalah handphone, laptop, software Microsoft Powerpoint 2010, dan Aiseesoft Total Video Converter. Sedangkan bahan yang digunakan adalah data dari hasil analisis ukuran dan tipe stomata, gambar/ foto, animasi, video, suara, dan rangkuman sub materi organ tumbuhan kelas XI SMA.

Langkah-langkah dalam penyusunan media interaktif sebagai berikut: (1) Melakukan analisis kurikulum; (2) Memilih teknologi yang digunakan yaitu software Microsoft Office Powerpoint 2010; (3) Merancang desain, (4) Menyusun storyboard; (5) Mengumpulkan media berupa gambar/foto, suara, animasi, dan video serta rangkuman; dan (6) Setelah bahan-bahan yang diperlukan lengkap, selanjutnya mengerjakan powerpoint interaktif organ tumbuhan dimulai.

Langkah-langkah dalam pembuatan powerpoint interaktif sebagai berikut: (1) Membuka program Microsoft Office Powerpoint 2010; (2) Menuliskan teks pada setiap slide sesuai naskah yang telah dibuat; (3) Memberi warna teks, 
disesuaikan dengan tingkat keterbacaan, kekontrasan, dan komposisi; (4) Membuat animasi teks, berupa efek gerakan pada teks atau gambar; (5) Memberi background, disesuaikan dengan sub materi organ tumbuhan; (6) Memasukkan gambar/foto dan animasi dengan teknik insert; (7) Memasukkan backsound dengan teknik insert yang sebelumnya dikonvesi terlebih dahulu menggunakan software Aiseesoft Total Video Converter; (8) Memasukkan video dengan teknik insert; (9) Membuat hyperlink; dan (10) Membuat evaluasi hasil belajar menggunakan aplikasi Visual Basic for Application (VBA) yang ada pada menu powerpoint.

Untuk mengetahui suatu media layak digunakan atau tidak, maka perlu dilakukan validasi. Sebelum media divalidasi maka dilakukan uji kelayakan instrumen validasi. Hal terebut dilakukan untuk menguji kelayakan isi pada lembar validasi dan indikator penskoran. Lembar uji kelayakan instrumen validasi dapat dianalisis dengan skala penilaian "Ya" atau "Tidak" untuk mendapatkan kesimpulan layak digunakan (LD), layak digunakan dan diperbaiki (LDP), dan tidak layak digunakan (TLD). Uji kelayakan instrumen dilakukan oleh 2 orang dosen Pendidikan Biologi FKIP Untan. Lembar instrumen validasi dapat digunakan jika kedua validator mengatakan semua kriteria disimpulkan layak digunakan.

Setelah lembar instrumen validasi dinilai layak digunakan (LD), maka dilakukan validasi media powerpoint interaktif dengan 3 aspek yang dinilai oleh ahli materi yaitu format, isi, dan bahasa dan 6 aspek yang dinilai oleh ahli media yaitu aspek kesederhanaan, keterpaduan, penekanan, keseimbangan, bentuk dan warna. Adapun skala yang digunakan adalah dengan nilai $4=$ Baik Sekali (BS), nilai 3 = Baik (B), nilai 2 = Kurang Baik (KB), dan nilai 1 = Tidak Baik (TB). Proses validasi dilakukan oleh 3 orang ahli materi dan 3 orang ahli media. Validator ahli materi terdiri dari 1 orang dosen dan 2 orang guru SMA, sedangkan validator ahli media terdiri dari 2 orang dosen dan 1 orang guru SMA. Guru yang dijadikan sebagai validator adalah guru yang berasal dari sekolah mitra. Pemilihan sekolah mitra menggunakan teknik purposive sampling. 


\section{HASIL DAN PEMBAHASAN}

Media powerpoint interaktif yang dibuat digunakan untuk membantu siswa dalam memahami sub materi organ tumbuhan di kelas XI SMA. Powerpoint yang dibuat ini tidak hanya bersifat audio visual namun juga bersifat interaktif, dimana berisi menu-menu sebagai sistem navigasi, tombol-tombol aktif untuk penjelasan singkat mengenai materi/keterangan gambar, narasi, animasi yang mendukung, video, soal-soal latihan setiap selesai pembahasan materi organ tumbuhan (akar, batang, daun dan bunga), dan evaluasi mandiri (Gambar 1).

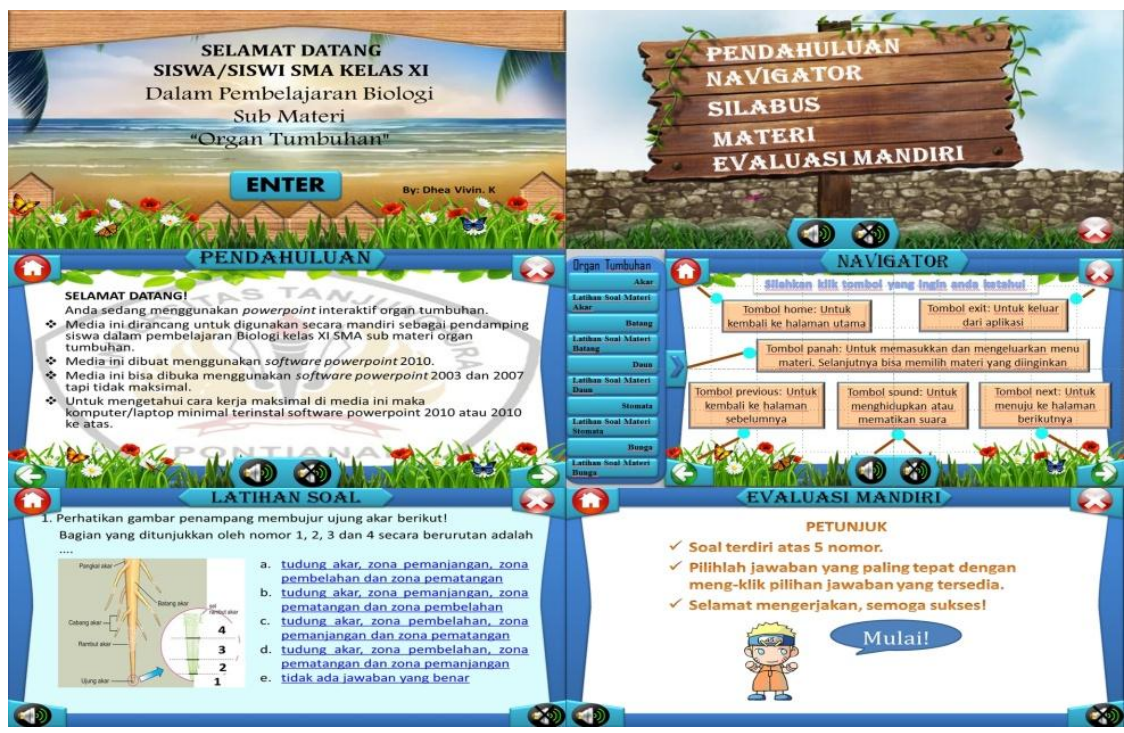

Gambar 1 Tampilan Powerpoint Interaktif Organ Tumbuhan

Media powerpoint interaktif yang sudah dibuat dinilai kelayakannya oleh 3 orang ahli materi dan 3 orang ahli media. Ahli materi terdiri atas 1 orang dosen Pendidikan Biologi dan 2 orang guru Biologi kelas XI SMA. Ahli media terdiri atas 1 orang dosen Pendidikan Fisika, 1 orang dosen Sistem Komputer, dan 1 orang guru Biologi kelas XI SMA.

Tabel 1 Analisis Data Hasil Validasi Media Powerpoint Interaktif Organ Tumbuhan oleh Ahli Materi

\begin{tabular}{|c|c|c|c|c|c|c|}
\hline \multirow{2}{*}{ Aspek } & \multirow{2}{*}{ Kriteria } & \multicolumn{3}{|c|}{ Validator } & \multirow{2}{*}{$\mathbf{K i}$} & \multirow{2}{*}{$\mathbf{A} i$} \\
\hline & & 1 & 2 & 3 & & \\
\hline \multirow[b]{2}{*}{ Format } & $\begin{array}{l}\text { 1. Kesesuaian warna, tulisan dan gambar } \\
\text { pada ppt interaktif }\end{array}$ & 4 & 4 & 4 & 4 & \\
\hline & $\begin{array}{l}\text { 2. Kesesuaian gambar dan tulisan pada } \\
\text { evaluasi bersama (latihan soal) dan } \\
\text { evaluasi mandiri }\end{array}$ & 4 & 4 & 4 & 4 & 4 \\
\hline
\end{tabular}




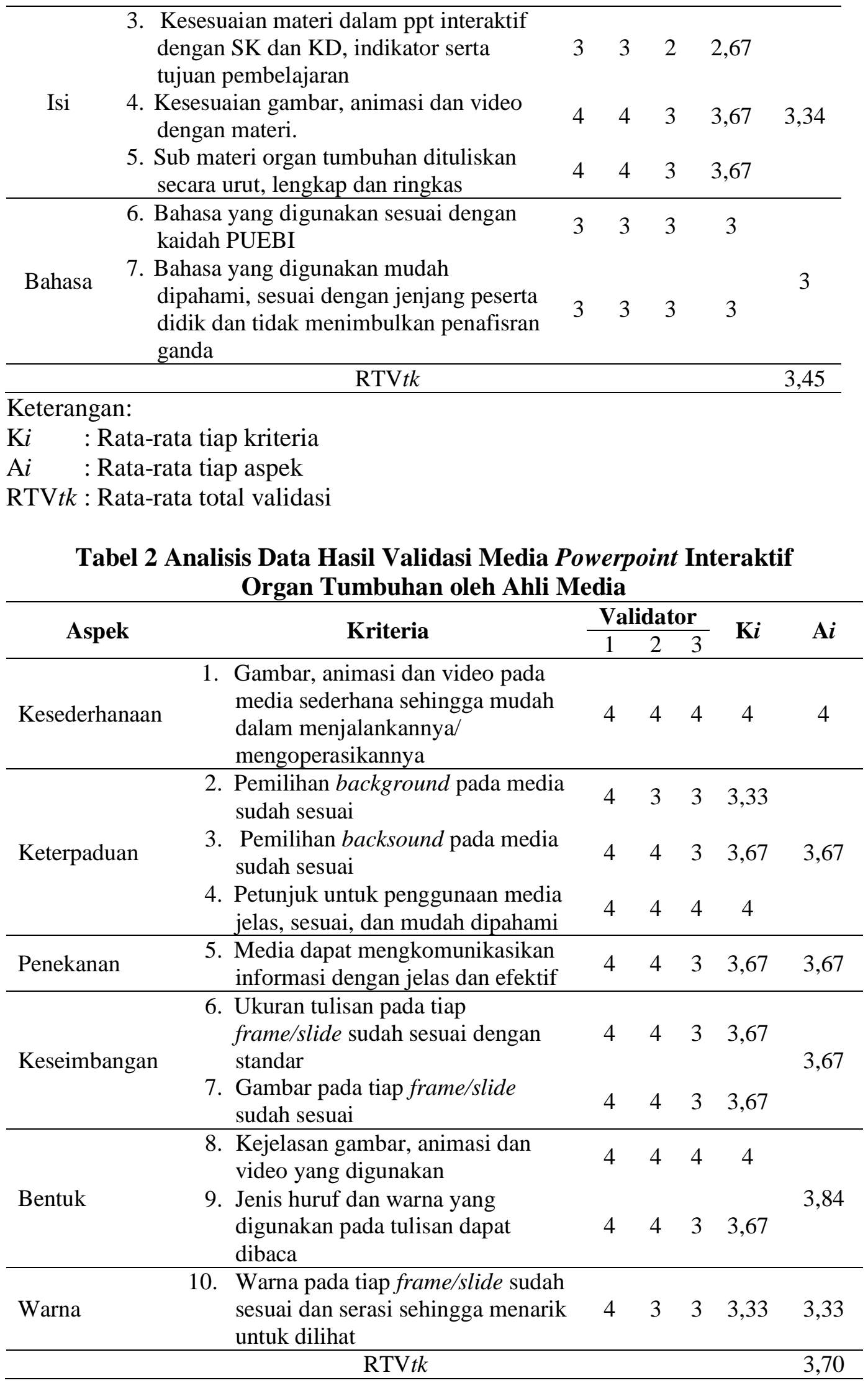


Keterangan:

$\mathrm{K} i \quad$ : Rata-rata tiap kriteria

$\mathrm{A} i \quad$ : Rata-rata tiap aspek

RTVtk : Rata-rata total validasi

Menurut Yamasari (2010), media dikatakan berkualitas jika telah memenuhi indikator: valid menurut para ahli, praktis, dan efektif. Berdasarkan hasil validasi media oleh ahli materi (Tabel 1), diperoleh skor rata-rata total validasi yaitu 3,45 dimana menurut kriteria kevalidan Khabibah (dalam Yamasari, 2010) jika ratarata total validasi $3 \leq R T V_{\mathrm{TK}} \leq 4$, maka media dikategorikan valid. Dari seluruh aspek yang dinilai mendapatkan skor valid, aspek-aspek tersebut meliputi.

\section{Aspek Format}

Validasi pada aspek format media powerpoint interaktif organ tumbuhan memperoleh rata-rata skor yaitu 4 dan berkateogri valid (Tabel 1). Hal tersebut berarti bahwa komponen pada media yang meliputi warna, gambar, dan tulisan dari hasil penilaian sesuai dengan materi pembelajaran serta evaluasi bersama dan evaluasi mandiri. Penggunaan warna, gambar, dan tulisan yang sesuai dapat membantu penyampaian materi-materi yang bersifat teoretis menjadi lebih konkrit melalui pointer-pointer materi pada powerpoint interaktif.

Maryani (2014) menjelaskan bahwa multimedia berbasis powerpoint merupakan penggunaan komputer untuk menyajikan dan menggabungkan teks, suara, gambar, animasi, dan video dengan alat bantu (tool) dan koneksi (link) sehingga pengguna dapat bernavigasi, berinteraksi, berkarya, dan berkomunikasi. Lebih lanjut lagi Munir (2013) menyebutkan bahwa perpaduan antara gambar, warna dan teks yang seimbang sangat perlu diperhatikan karena hal tersebut membuat media secara visual lebih menarik.

\section{Aspek Isi}

Validasi media powerpoint interaktif organ tumbuhan pada aspek isi memperoleh rata-rata skor 3,34 dan berkategori valid (Tabel 1). Hal tersebut berarti bahwa rumusan materi dalam powerpoint interaktif sesuai dengan $\mathrm{SK}, \mathrm{KD}$, indikator, dan tujuan pembelajaran. Tampilan gambar atau animasi atau video dalam media juga sudah sesuai dengan materi pembelajaran yang akan 
disampaikan. Gambar, animasi, dan video dapat menyampaikan konsep yang abstrak menjadi konkrit. Menurut Dale (Asyhar, 2012), gambar dapat merubah tahap-tahap pembelajaran dari lambang kata (verbal symbol) beralih pada tahapan yang lebih konkrit yaitu lambang visual (visual symbol). Sub materi organ tumbuhan dituliskan secara urut atau lengkap dan ringkas sehingga dapat memfasilitasi proses pembelajaran.

Salah satu kriteria yaitu kesesuaian materi dalam powerpoint interaktif dengan SK dan KD, indikator serta tujuan pembelajaran diantara ketiga validator ada yang memberikan nilai 2 dari salah satu validator. Validator tersebut memberikan saran untuk menggunakan SK dan KD terbaru (Kurikulum 2013), pengembangan indikator dan tujuan disesuaikan juga dengan Kata Kerja Operasional yang diurutkan dari tingkat aspek kognitif terendah (C1) sampai tingkat tertinggi (C6), gambar organ batang diganti dengan yang lebih jelas, dan penambahan pada materi batang (floem dan xylem lebih spesifik).

Kelebihan Kurikulum 2013 yang terbaru adalah materi pembelajaran yang disampaikan lebih spesifik karena telah membahas tentang struktur stomata lebih spesifik. Alokasi pembelajaran lebih lama jika dibandingkan dengan KTSP. Namun kenyataannya yang ada adalah Kurikulum 2013 yang terbaru tersebut belum disosialisasikan dan diimplementasikan secara resmi. Media yang disusun berdasarkan kurikulum yang sudah ada dan resmi digunakan. Gambar anatomi organ batang diganti dengan yang lebih jelas sehingga siswa dapat membedakan secara tepat masing-masing bagian anatomi organ batang tersebut dan penambahan pada materi batang pada penjelasan bagian floem dan xylem yang lebih spesifik agar komposisi materinya seimbang.

\section{Aspek Bahasa}

Validasi media powerpoint interaktif pada aspek bahasa memperoleh ratarata skor 3,00 dan berkategori valid (Tabel 1). Semua validator memberikan nilai 3. Berdasarkan rubrik yang diberikan nilai 3 (baik) hanya memenuhi 2 dari 3 variabel pada nilai 4 (sangat baik) yaitu bahasa yang digunakan cukup sesuai dengan kaidah PUEBI, mudah dipahami atau sesuai dengan jenjang peserta didik dan tidak menimbulkan penafsiran ganda. Dengan demikian semua validator 
mempunyai persepsi yang sama, sehingga perlu perbaikan dari sudut bahasanya sebelum diimplementasikan lebih jauh lagi. Penggunaan bahasa yang sesuai dengan PUEBI, mudah dipahami dan sesuai dengan jenjang peserta didik serta tidak menimbulkan penafsiran ganda dapat membantu penyampaian materi pembelajaran lebih mudah dipahami. Bahasa yang mudah dipahami adalah salah satu tanda kemudahan penggunaan media (Sadiman, dkk., 2010).

Selanjutnya berdasarkan hasil validasi oleh ahli media (Tabel 2), diperoleh skor RTV sebesar 3,70. Berdasarkan kriteria kevalidan yang dikemukakan oleh Khabibah (Yamasari, 2010), jika RTV $3 \leq R T V_{\mathrm{TK}} \leq 4$, maka media dikategorikan valid. Dari seluruh aspek yang dinilai mendapatkan skor valid, aspek-aspek tersebut meliputi.

\section{Aspek Kesederhanaan}

Validasi media powerpoint interaktif organ tumbuhan pada aspek kesederhanaan memperoleh skor yaitu 4 dan berkategori valid (Tabel 2) yang menunjukkan bahwa gambar, animasi, dan video pada powerpoint interaktif yang dibuat sederhana dan mudah dalam menjalankan/mengoperasikannya. Hal tersebut sesuai dengan prinsip penggunaan media pembelajaran yang menurut Sanjaya (2008), media yang digunakan harus mudah dalam pengoperasiannya.

Kustandi dan Sutjipto (2013) menyatakan bahwa sebuah media harus mudah dalam penggunaannya atau "ease of use/ user friendly" dan media tersebut dapat bersahabat dengan penggunanya. Setiap instruksi dan paparan informasi bersifat membantu penggunaan media, termasuk kemudahan pengguna dalam merespon dan mengakses sesuai keinginan. Salah satu bentuk user friendly adalah penggunaan bahasa yang sederhana, gambar, animasi, dan video yang jelas serta mudah dimengerti.

\section{Aspek Keterpaduan}

Validasi media powerpoint interaktif organ tumbuhan pada aspek keterpaduan memperoleh skor sebesar 3,67 dan berkategori valid (Tabel 2) yang menunjukkan bahwa pemilihan background dan backsound serta petunjuk untuk penggunaan media sudah lebih baik. Background yang digunakan tidak lebih terang daripada objek yang ditampilkan namun terlihat menyeluruh. Penggunaan 
bakcsound jelas atau sesuai dan tidak mengganggu pengoperasian media. Petunjuk untuk penggunaan media jelas atau sesuai dan mudah dipahami. Setiap instruksi dan paparan informasi bersifat membantu penggunaan media. Hal tersebut sesuai dengan yang dikemukan oleh Hofstetter (Munir, 2013), multimedia interaktif merupakan suatu integrasi beberapa elemen media yang menjadi satu kesatuan dengan link dan tool yang bermanfaat bagi pengguna media.

\section{Aspek Penekanan}

Validasi media powerpoint interaktif organ tumbuhan pada aspek penekanan memperoleh skor sebesar 3,67 dan berkategori valid (Tabel 2) yang menunjukkan bahwa media dapat menyampaikan informasi lebih jelas. Informasi yang jelas disampaikan secara spesifik yaitu menekankan pada anatomi beberapa organ tumbuhan (Gambar 2).

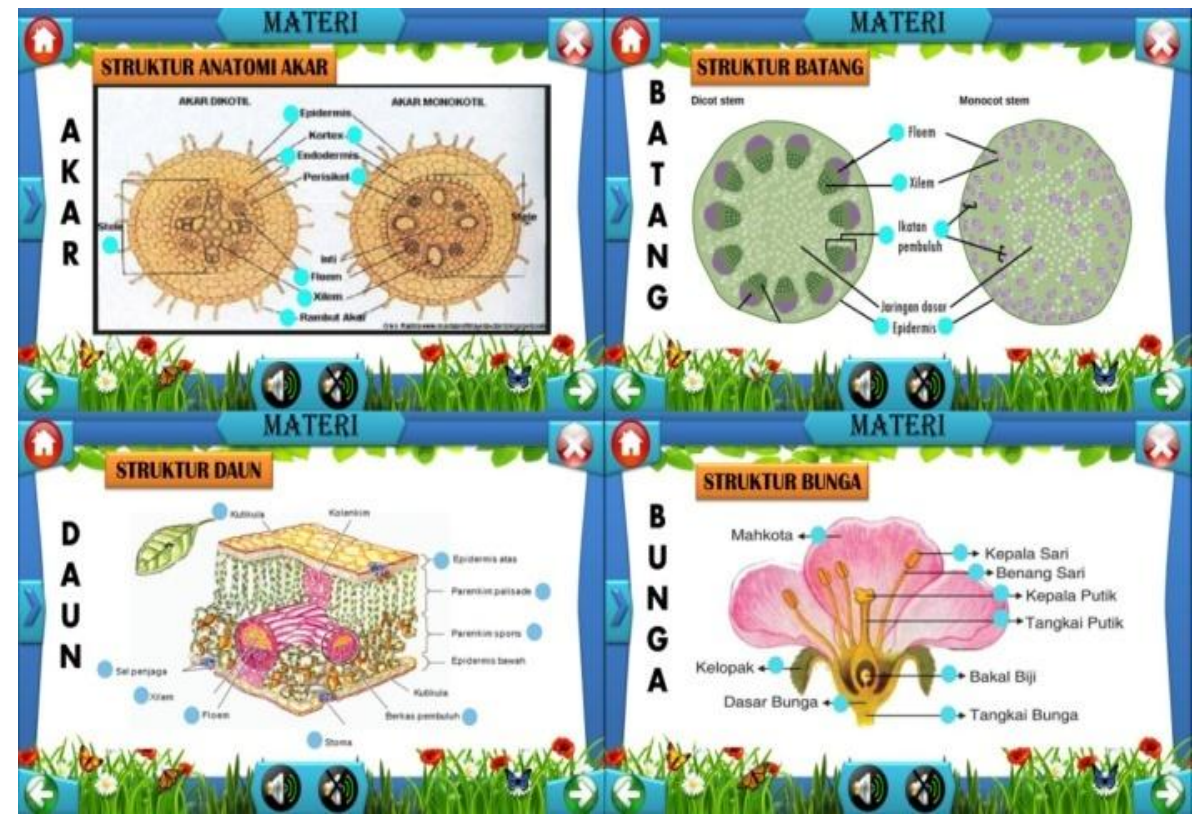

Gambar 2 Tampilan Media pada Materi Anatomi Organ Tumbuhan

\section{Aspek Keseimbangan}

Validasi media powerpoint interaktif organ tumbuhan pada aspek keseimbangan memperoleh skor sebesar 3,67 dan berkategori valid (Tabel 2) yang menunjukkan bahwa ukuran huruf yang digunakan sesuai dengan standar yaitu 
ukuran huruf 17-22 untuk isi teks, untuk sub judul 24-28, dan untuk judul 30-36 (Daryanto, 2010). Ukuran gambar yang ditampilkan dapat diamati dengan jelas atau konsisten dan tidak melebihi ukuran tampilan frame. Gambar yang digunakan dalam media jelas dan cukup besar, gambar yang tajam dan kontras memiliki kelebihan dalam menggambarkan kenyataan secara lebih baik (Munir, 2013). Tata letak gambar tidak melebihi area tampilan frame $(16 \times 20 \mathrm{~cm})$ (Daryanto, 2010). Berdasarkan validasi oleh ahli media terdapat revisi pada aspek keseimbangan, yaitu tulisan ada yang melebihi area tampilan frame, maka perlu perbaikan agar komposisi tulisan seimbang dan proporsional sehingga menarik untuk dilihat.

\section{Aspek Bentuk}

Validasi media powerpoint interaktif organ tumbuhan pada aspek bentuk memperoleh skor sebesar 3,84 dan berkategori valid (Tabel 2) yang menunjukkan bahwa gambar, animasi, dan video yang digunakan lebih jelas. Gambar yang ditampilkan meliputi gambar organ tumbuhan, anatomi masing-masing organ tumbuhan, dan foto preparat yang telah diamati, gambar jelas dan dapat menyajikan konsep materi sehingga membuat media menjadi lebih menarik. Animasi yang ditampilkan adalah animasi proses membuka dan menutupnya stomata dan video yang digunakan adalah video proses fotosintesis. Menurut Munir (2013), menggunakan animasi dan video dapat memperlihatkan atau memvisualisasikan materi pembelajaran yang berkaitan dengan proses yang tidak dapat dilihat dengan mata. Melalui visualisasi yang disajikan melalui animasi dan video, maka peserta didik akan lebih mudah memahami materi pembelajaran.

Jenis huruf yang digunakan konsisten atau tingkat keterbacaannya tinggi dan pemilihan warna yang tepat sehingga tulisan dapat dibaca. Ukuran huruf yang digunakan pada powerpoint interaktif adalah Algerian untuk judul dan Calibry untuk sub judul. Hal tersebut sesuai dengan yang dikemukakan oleh Daryanto (2010) bahwa dalam pembuatan bahan presentasi dengan menggunakan Microsoft Powerpoint, jenis huruf yang digunakan tingkat keterbacaannya tinggi, misalnya Arial, Calibry, Verdana atau Tahoma. Kemudian untuk warna tulisan yang digunakan pada powerpoint interaktif adalah warna hitam pada background biru 
untuk judul, background jingga untuk sub judul, background coklat muda untuk poin penjelasan, dan background putih untuk isi pada area frame dan warna tulisan putih untuk background coklat pada papan petunjuk isi media sehingga tulisan dapat dibaca.

\section{Aspek Warna}

Validasi media powerpoint interaktif organ tumbuhan pada aspek warna memperoleh skor sebesar 3,33 dan berkategori valid (Tabel 2) yang menunjukkan warna yang digunakan sesuai walau kurang serasi tetapi masih menarik untuk dilihat. Warna merupakan elemen grafik yang kuat, pemilihan warna yang sesuai dapat meningkatkan efektivitas media (Daryanto, 2010).

Nilai pada aspek warna oleh ahli media mendapatkan nilai yang berbeda/kontradiktif dengan penilaian oleh ahli materi. Hal tersebut dikarenakan salah satu validator ahli media secara lisan menyebutkan bahwa warna pada media terlalu monoton, sedangkan validator ahli media yang lain mengatakan bahwa jumlah warna terlalu banyak atau bervariasi. Berbeda halnya pada ahli materi yang memberikan nilai sempurna yaitu 4 (Tabel 1). Warna media yang monoton secara visual akan membuat media menjadi kurang menarik dan akan menyebabkan kebosanan pada siswa, sedangkan warna yang terlalu bervariasi akan membuat mata kurang fokus secara visual dalam penggunaan media.

Media dikatakan praktis jika media dapat digunakan dengan sedikit atau tanpa revisi/perbaikan (Yamasari, 2010). Berdasarkan hasil validasi oleh ahli materi dan ahli media, media berkategori cukup praktis dengan beberapa revisi atau perbaikan. Revisi dilakukan sesuai dengan saran dari keenam validator agar media lebih baik dan menarik apabila dilakukan penelitian lanjutan terhadap media.

\section{SIMPULAN}

Media powerpoint interaktif organ tumbuhan yang dibuat layak digunakan dalam pembelajaran Biologi kelas XI SMA pada sub materi organ tumbuhan dengan skor rata-rata total validasi (RTV) yang didapatkan adalah 3,45 oleh ahli 
materi dan 3,70 oleh ahli media. Hal tersebut berarti media powerpoint interaktif yang dirancang layak untuk digunakan.

\section{UCAPAN TERIMA KASIH}

Terima kasih kepada tim payung penelitian tentang analisis ukuran dan tipe stomata dengan dana mandiri dan Ketua Laboratorium Pendidikan Biologi FKIP Untan yang telah memfasilitasi untuk penelitian media powerpoint interaktif organ tumbuhan. Terima kasih pula kepada SMA Negeri 9 Pontianak, SMA Bina Mulia Pontianak, dan SMA Santun Untan Pontianak yang telah memberikan izin untuk validasi media powerpoint interaktif organ tumbuhan.

\section{DAFTAR PUSTAKA}

Asmadji, H. 2012. Penggunaan Media Pembelajaran Powerpoint Untuk Meningkatkan Hasil Belajar IPA Materi Pesawat Sederhana Siswa Kelas V C SDN Ketabang I Surabaya. Prosiding, Seminar Nasional. Surabaya: FKIP UNESA.

Asyhar, R. 2012. Kreatif Mengembangkan Media Pembelajaran. Jakarta: Referensi Jakarta.

Daryanto. 2010. Media Pembelajaran. Yogyakarta: Gava Media.

Djamarah, S. B. \& Aswan, Z. 2010. Strategi Belajar Mengajar. Jakarta: Rineka Cipta.

Kenthut. 2010. Pembuatan Media Presentasi. Jakarta: Pusat Teknologi Informasi dan Komunikasi Pendidikan Kementerian Pendidikan Nasional.

Kustandi, C. \& Sutjipto, B. 2013. Media Pembelajaran. Bogor: Ghalia Indonesia.

Maryani, D. 2014. Pembuatan Media Pembelajaran Interaktif Bangun Ruang Matematika. Journal Sentra Penelitian Engineering dan Edukasi, 6(2): $18-24$.

Munir. 2013. Multimedia Konsep dan Aplikasi dalam Pendidikan. Bandung: Alfabeta.

Nisa, A. F. 2012. Media Powerpoint dalam Peningkatan Hasil Belajar pada Pembelajaran Sains di Kelas IV MI Ma'Had Islamy Kotagede Yogyakarta. Skripsi. Yogyakarta: FTK UIN Sunan Kalijaga. 
Raras, K. L. H. 2012. Pengaruh Penggunaan Media Powerpoint terhadap Peningkatan Motivasi dan Hasil Belajar pada Mata Pelajaran IPA Siswa Kelas V SD SN Batursari 6 Kecamatan Mranggen Kabupaten Demak. Skripsi. Salatiga: FKIP Universitas Kristen Satya Wacana.

Sadiman, A. S., Rahadjo, R., Anung, H., \& Rahardjito. 2010. Media Pendidikan. Jakarta: Rajagrafindo Persada.

Sanjaya, W. 2008. Perencanaan dan Desain Sistem Pembelajaran. Jakarta: Kencana.

Suyono \& Nugroho, G. K. 2011. Optimalisasi Microsoft Office Powerpoint 2010 dalam Pembuatan Media Interaktif Penggandaan Dokumen untuk Program Keahlian Administrasi Perkantoran Sekolah Menengah Kejuruan Negeri 1. Journal Sentra Penelitian Engineering dan Edukasi. 4(2): 29-37.

Yamasari, Y. 2010. Pengembangan Media Pembelajaran Matematika Berbasis ICT yang Berkualitas. Seminar Nasional Pascasarjana X. Surabaya: FMIPA Unesa. 